\title{
Development of Water Meter Intruder Alarm System
}

\author{
Emmanuel Mdemu ${ }^{1}$ and Noel Chintelele ${ }^{2}$ \\ ${ }^{1}$ Undergraduate and ${ }^{2}$ Assistant Lecturer \\ Department of Information and communication Technology \\ Mbeya University of Science and technology \\ Mbeya, Tanzania
}

\begin{abstract}
The current system of water supply was not protected by any system of intrusion which lead to intruders steal those water meters by believing that those meter will help them on one way or another due they were not protected. The aim of this project is develop an intruder alert system which will help to chase away those thieves or help to catch them and will alert the owner of the meter and water supply authority through Short Message Service (SMS) about the intrusion. GSM technology will be integrated for this Short Message Service (SMS) which will require input signals from the sensor and make relays trigger output signal for sending this SMS.
\end{abstract}

Key Words: Water meter intruder, Water meter protection, Intruder alert system, Elimination of water meter theft.

\subsection{INTRODUCTION}

This part consists of background study, problem statement and scope of the project where by those area describes different reviews about water meter as follows; -

\subsection{Background study}

Water meters are found in residential and commercial buildings that use a public water supply system. These meters are designed to keep track of how much water is consumed by a particular household or business.

The most common types of water meters are:

$>$ Displacement (Positive) Water Meters

$>$ Velocity Meters

\section{Displacement (Positive) Water Meters}

Displacement water meters, often called Positive Displacement (PD) meters, are the most common water meters for residential and small commercial properties. They're great for measuring small volumes of water at low flow rates. They contain mechanical parts (an oscillating piston or nutating disk) that are displaced, or moved, as water flows through the meter's main chamber. These moving parts measure the volume of water and increase the reading on your meter's register by the appropriate amount. [1]

\section{Velocity Meters}

Velocity water meters are also known as internal capacity meters. These meters are designed to determine the volume of water that has flowed through the meter based on the speed of the flow. Within the velocity flowmeters category are the following subcategories:

$>$ Multi-jet

$>$ Turbine

$>$ Compound 
Multi-jet meters are used when a high level of accuracy is required in a small space. These meters use multiple ports that surround an internal chamber. Each port creates a jet of water that hits an impeller. Ultimately, the rotation of the impeller determines the amount of water that has passed through the meter. [2]

The current water meters installed to our premises are called multi jet dry type, brand name is Baylan Aquamas [3]. Those devices were made by the combination of different materials like copper, plastic and glass. In this devices there were different rotation gears which used to record water consumption when the tap of water opened, gears rotation is caused by pressure of water which was passing through the meter to water taps when it opened [4].

These meters are installed in U-shaped structure on the ground level to enable easy access when taking readings of water consumed on that month [5]. This U shape structure consists of upstream from the ground level which inlet water from the taped source and downstream which outlet water to the customer consider the following diagram; -

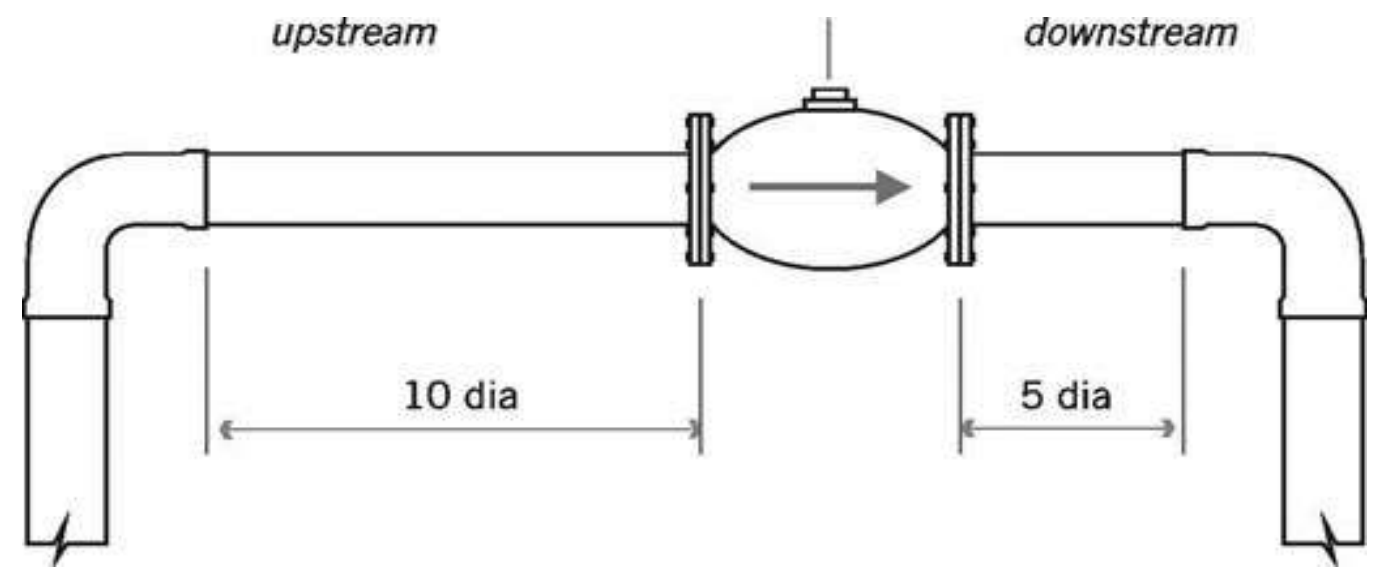

Figure 1. U shaped water meter installation structure on earth ground level

\subsection{Problem statement}

Water meters are usually installed outside of residential buildings or commercial buildings so as to enable meter reading staffs to access it easily during meter reading time.

Then there are intruders used to steal those meters by believing that they will collect copper material which was in that device and go to sell due to their expensiveness or thinking of reselling those meters or steeling by thinking they can repair the defective one on their premises or to other customers.

Due to this problem can lead to loss of water unnecessarily, lack of water from supplier, time consuming during requisition of new meter and wastage of money for buying new water meter.

Therefore, intruder alarm system proposed will help to protect water meters in case of intruder start opening the meter during stealing, this system will help to alert the owner and water authority, catch the intruders easily and the challenges above will be solved.

\subsection{Scope of project}

The scope of the project is to design a system, create simulation of the system and develop a working prototype.

\subsection{ProjeCt SIGNIFICANCE AND OBJECTIVES}

This part consists of project significant, project objectives and knowledge contribution as follows; -

\subsection{Project significant}

Significant of this project are elimination of water meter theft, save unnecessary cost of water meter replacement incurred by customer when his or her meter was stolen, will help to alert the owner of water meter and water authority through GSM technology which was integrated in this project and it will help to catch the intruders easily during stealing process because the system has siren which used to notify the owner. 


\subsection{Project objectives}

The objective of this project is characterized into two categories which are main objective and specific objective as follows: -

\subsubsection{Main objective}

The main objective is to develop water meter intruder alert system for water meter protection and catching up intruders.

\subsubsection{Specific objectives}

i. To design circuit on the breadboard

ii. To configure electronic components

iii. To program microcontroller

iv. To integrate microcontroller with GSM Dialer

v. To simulate the complete system

vi. To implement the system prototype

\subsection{Knowledge contribution}

Development of this system lead to knowledge contribution to the society because the current system of water meter supply does not have any protection which lead to easily meter theft in our residence.

\subsection{METHODOLOGY}

These methodologies include specific activities for the analysis and design of both the data and process portions of the system.

\subsection{Data analysis}

Systems analysis works with tangible things and activities and how they act and interact today. Systems analysis also works with data and procedures and their interaction.

The followings are the modern approach used to explain on how interaction of the system with the user are and how the system perform all the activities programmed to do; -

1. Block diagram

2. Use case diagram

3. Sequence diagram

\subsection{Block diagram}

A block diagram is a diagram of a system in which the principal parts or functions are represented by blocks connected by lines that show the relationships of the blocks. Block diagram does not show all activities that the system should do. 


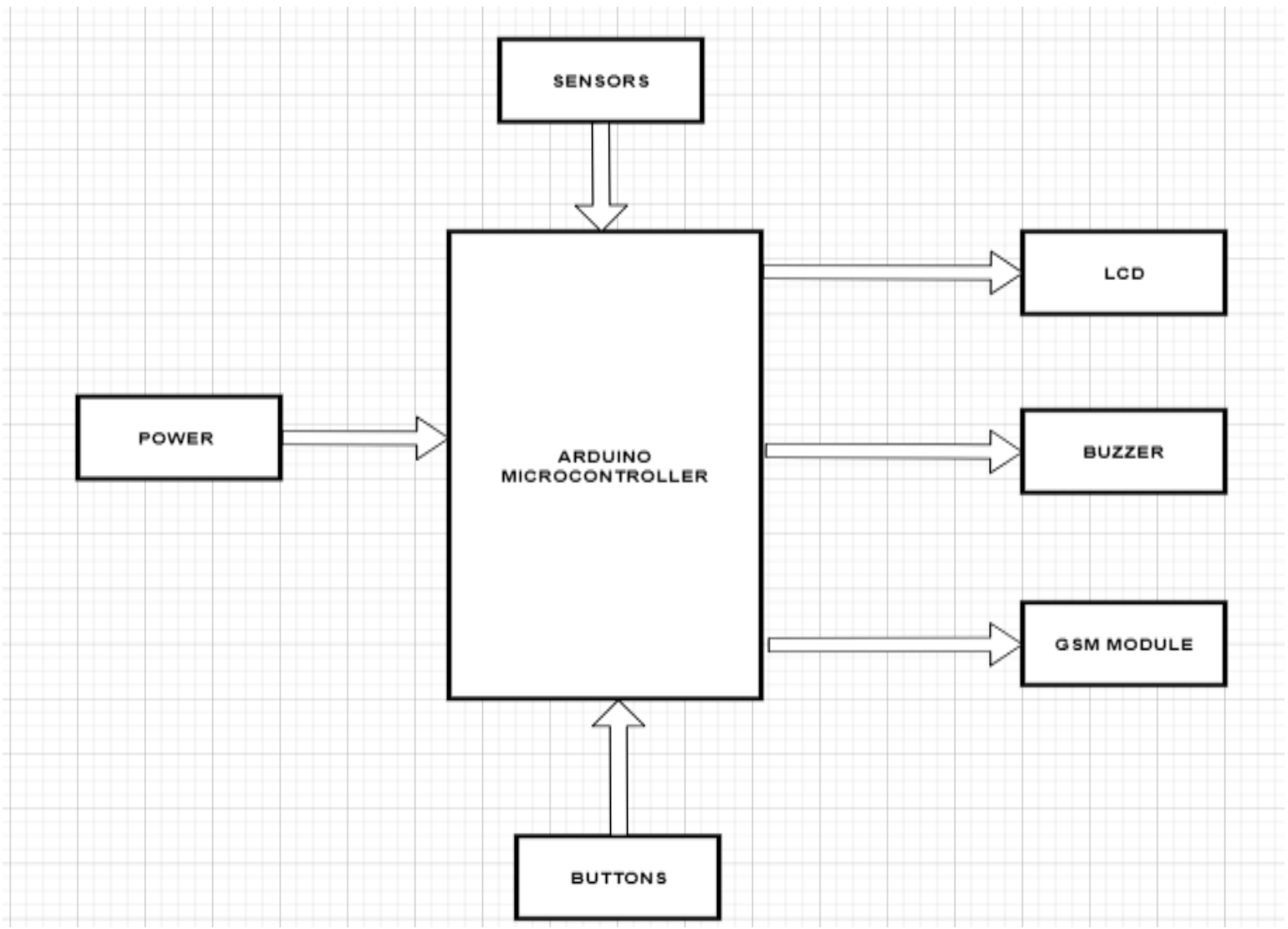

Figure 2 block diagram

\subsubsection{Flow diagram}

Use case diagram is a representation of a user's interaction with the system that shows the relationship between the user and the different use case in which user involved. Also can identify the different types of users of a system and the different use cases and will often be accompanied by other types of diagrams as well.

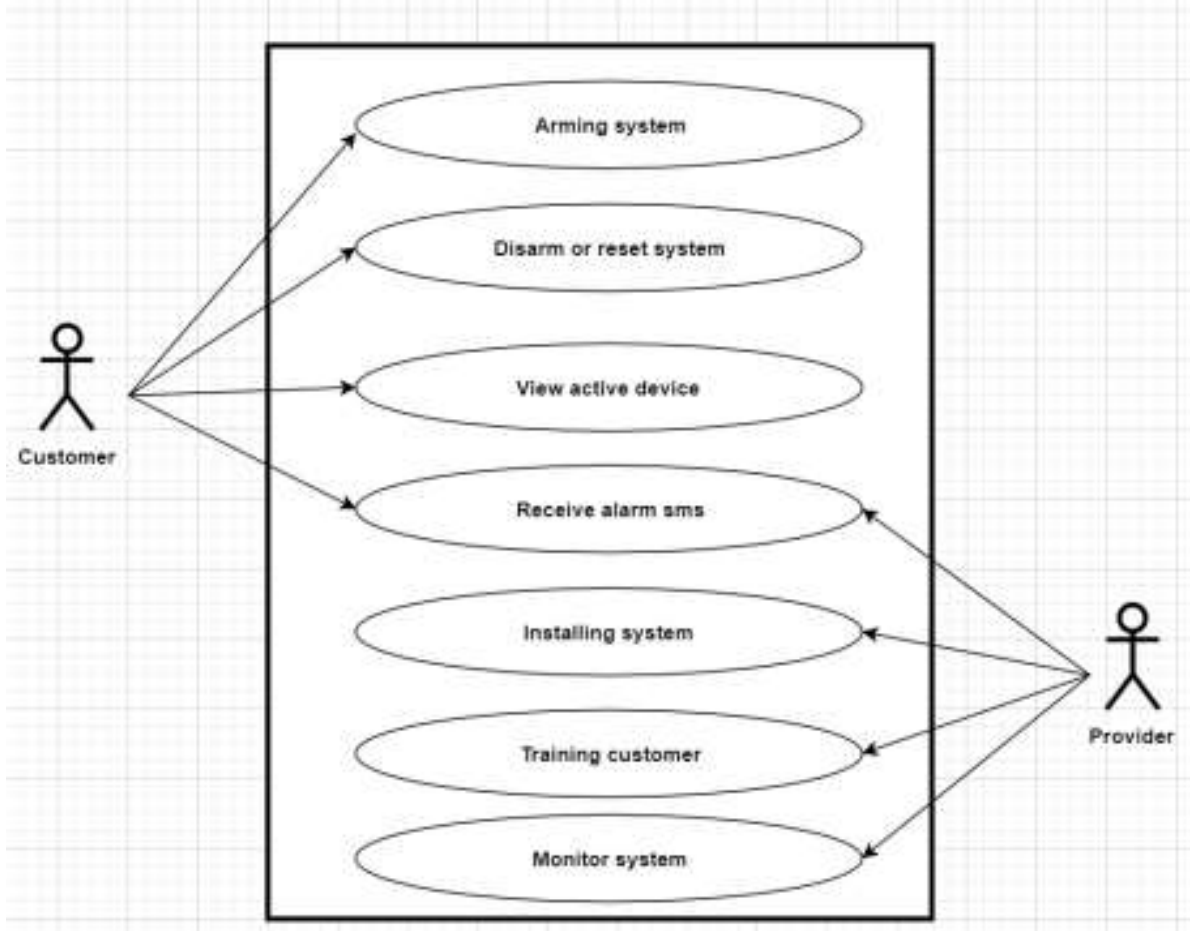

Figure 3. Flow diagram 


\subsubsection{Sequence diagram}

A sequence diagram is a good way to visualize and validate various runtime scenarios. It describes interactions among classes in terms of an exchange of messages or signals over time.

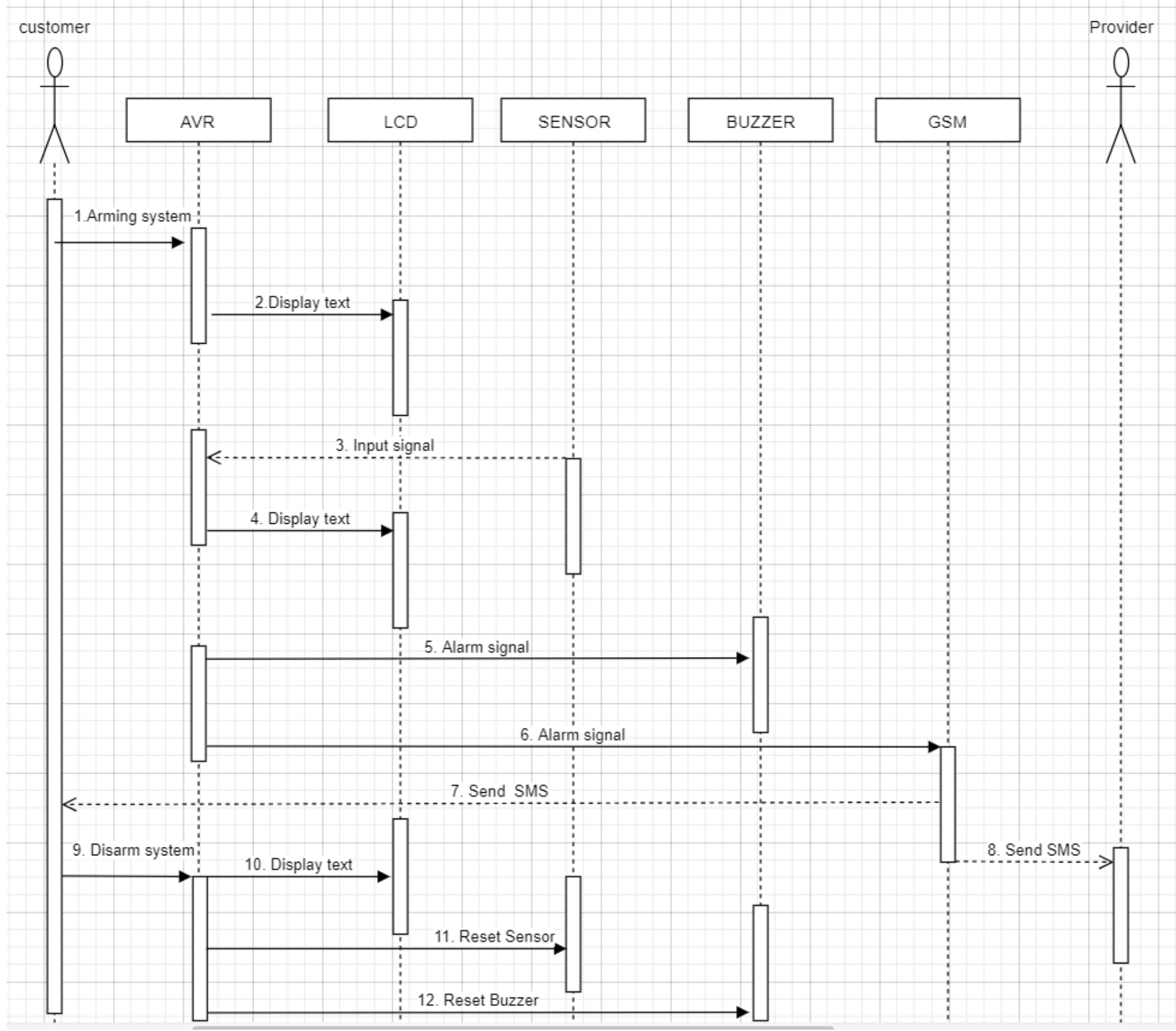

Figure 4 Sequence diagram

\subsection{System design}

Systems design is the development of a framework within which those activities must be performed. That framework is what provides order and harmony to the whole. The design may be taken to any level of detail necessary, or possible to fully describe what must changes be made and how, when and where they must be made. Before designing a prototype simulation should be conducted first

\subsubsection{Simulation}

A simulation is an animated model that mimics the operation of an existing or proposed system. The act of simulating first requires a model is developed, this model is a well-defined description of the simulated subject, and represents its key characteristics, such as its behavior, functions and abstract or physical properties.

The following is the complete working model of water meter intruder alarm system which was simulated in Proteus software; - 


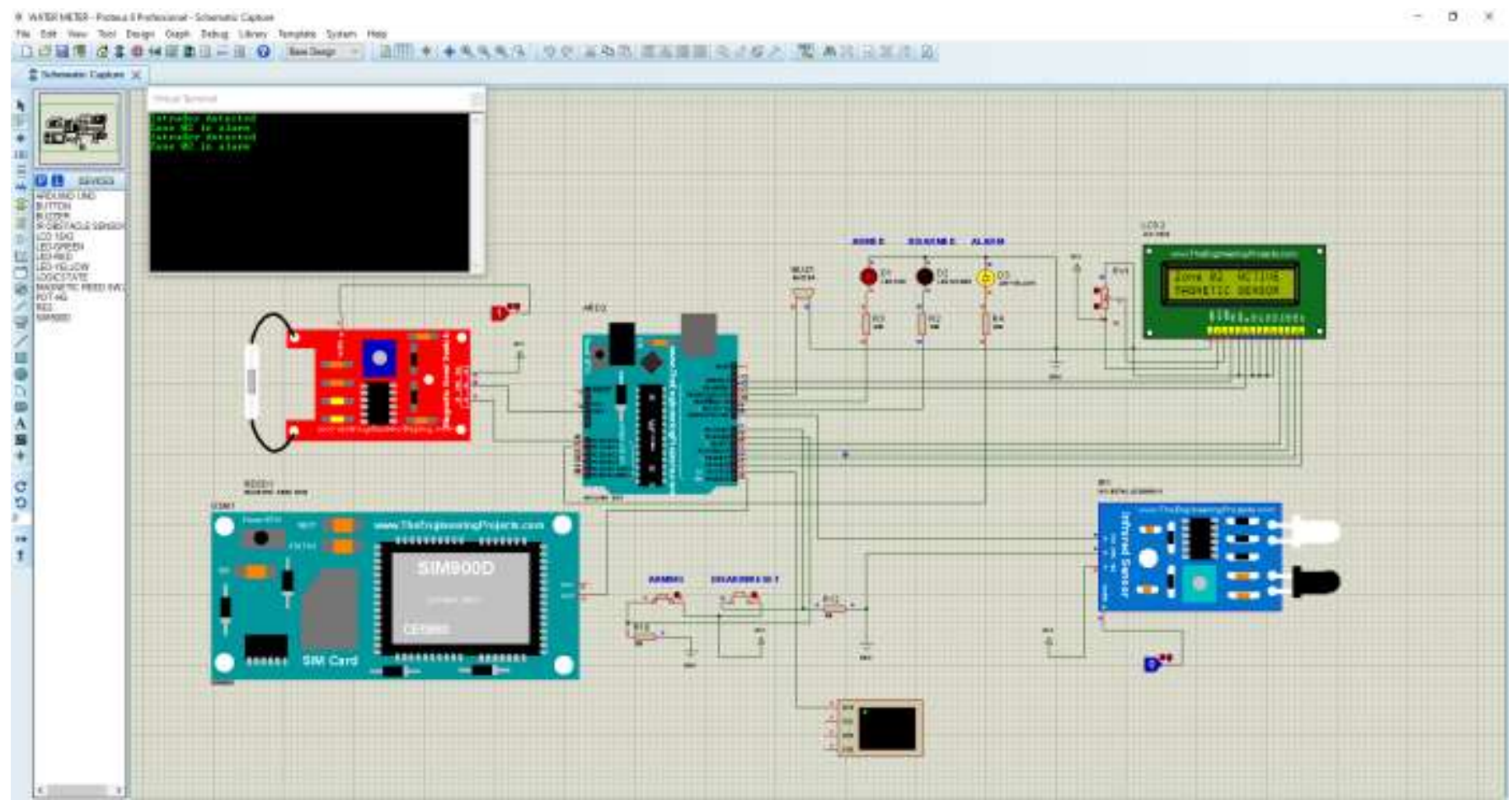

Figure 5 System model simulation

\subsubsection{Prototype designing}

A prototype is a draft version of a product that allows you to explore your ideas and show the intention behind a feature or the overall design concept to users before investing time and money into development. A prototype can be anything from paper drawings (low-fidelity) to something that allows click-through of a few pieces of content to a fully functioning site (high-fidelity).

This water meter intruder alarm system consists of materials which when integrated together form a complete protection system which will be useful to secure water meters in our domestics, the system consists of one microcontroller (Funduino uno), two laser sensors, two magnetic contacts, three Light emitting diodes (LED), one liquid crystal display (LCD), one potentiometer, one buzzer, six resistors, two push buttons and one GSM module.

The components used for the prototype build up where as listed below:

$>$ Microcontroller (Funduino UNO R3)

$>$ Laser photoelectric sensor (NPN)

$>$ Light emitting diodes (Red, Green and Yellow)

$>$ GSM module SIM900

$>$ Liquid Crystal Display (1602LCD Screen)

$>$ Active buzzer

$>$ Potentiometer (10k)

$>$ Resistors (10k and 220ohm)

$>$ Push buttons

$>$ Magnetic contact(DC)

\subsection{SUMMARY OF RESULTS}

When the system is powered all devices become active, the input signal will be generated from the sensors once the sensor was violated or alarm cable was disturbed and the generated signal will be sent to the microcontroller. Then microcontroller produce an output signal which make buzzer sound an alarm and other output signal make GSM module to send SMS to the customer mobile phone and to water authority about the intruder alarm while LCD display will show zone name which produce an alarm also when system is in normal state (ready to arm), when the system is armed and when the system disarmed. LED will show light color code according to the labels on the system. 
Buzzer and GSM module will work when the system is armed and when the system disarmed LED yellow will indicate an alarm when sensor was violated or alarm cable disturbed without ringing buzzer or send SMS to the mobiles through GSM

\title{
5.0 CONCLUSION AND RECOMMENDATIONS
}

\subsection{CONCLUSION}

This paper was designed to eliminate water meter theft, save unnecessary cost of water meter replacement incurred by customer when his or her meter was stolen, will help to alert the owner of water meter and water authority through GSM technology which was integrated in this project and it will help to catch the intruders easily during stealing process because the system has siren which used to notify the owner.

The data needed for design of the system are being successfully collected and analyzed then used to build circuit. Through this report, it has been proved that the design has met the main objectives (To develop water meter intruder alarm system) and specific objective of designing the appropriate circuit for such operation, running simulation and building a prototype. Therefore, the main idea of this project will help to improve discipline, facilitate performance of workers and provide comfortability to their customers since their water meter will be in good protection at their premises.

\subsection{Recommendations}

Apart from water services which customers got from water authority, water meter require protection which they lack now on the current system because water meter is the main tool which enable customer to use water from the source. I highly recommend that the system should be implemented so that to simplify management and provide protection of water meters.

This project can be further modified by any student from any department. In the future, I recommend to implemented more features so that to improve system performance and protection which will be useful even to disabled people also by making it flexible in which it can allow interfacing microcontroller with advanced security systems in the world.

\author{
List of Abbreviations \\ MUST - Mbeya University of Science and Technology \\ SMS - Short Message Service \\ GSM - Global System for Mobile communication \\ PSPP - Persatuan Sepakbola Padang Panjang \\ LCD - Liquid Crystal Display \\ LED - Light Emitting Diode \\ PD - Positive Displacement \\ DC - Direct Current
}

\section{REFERENCE}

The followings are the most areas used in this project report as a reference citation; -

[1] "TYPES OF WATER METERS," 2019. [Online]. Available: https://alertlabs.zendesk.com/hc/en-us/articles/115001268973Types-of-water-meters.

[2] "Exploring the Different Types of Water Meters," 2017. [Online]. Available: https://flowmetrics.com/exploring-types-watermeters/.

[3] Aquamas, " Flow system," AQUAMAS, NAIROBI, 2012.

[4] Baylan, "Baylan," 2006. [Online]. Available: http://www.baylanwatermeters.com/en/products_en.php?cat=18\#product-cat-2.

[5] "Diagram of water meter installation," 2019. [Online]. Available: http://17.1.travelmate-nz.de/dash/diagram-of-water-meter- 

install.html.

[6] H. P. Degeling, Evalutaing Promotion, 1990.

[7] S. A. McLeod, Sampling Methods, 2014.

[8] P. J. Lavrakas, Encyclopedia of Survey Research Methods, 2008.

[9] "Tanzania-southernhighlands," 2012. [Online]. Available: http://www.citypopulation.de/php/tanzania-southernhighlandsadmin.php?adm1id=1208.

[10] S. Greener, Business Research Methods, Maersk: Dr. Sue Greener \& Ventus Publishing Aps., 2008.

[11] J. Dudovskiy, The Ultimate Guide to Writing a Dissertation in Business Studies, 2018.

[12] "GNU OPERATING SYSTEM," 2013. [Online]. Available: https://www.gnu.org/software/pspp/. 